\title{
Diversity of deep-water cetaceans and primary productivity
}

\author{
Hal Whitehead*, Kristin O'Brien, Boris Worm
}

Department of Biology, Dalhousie University, Halifax, Nova Scotia B3H 4J1, Canada

\begin{abstract}
Recently, it has been suggested that mammal diversity both on land and in the sea is controlled by patterns of primary productivity. Here we tested the hypotheses that large-scale patterns of marine mammal diversity are linked to primary productivity, sea surface temperature (SST) or a combination of these 2 factors. We used a consistently sampled sightings database of deep-water cetaceans in the Atlantic and Pacific Oceans, along with in situ SST measurements and 3 satellite-derived productivity measures matched spatially and temporally to available sightings. Cetacean genus richness peaked in regions of high primary productivity ( $>1000$ to $1500 \mathrm{mg}$ $\mathrm{C} \mathrm{m}^{-2} \mathrm{~d}^{-1}$ ), but most of this effect is captured by optimal SST in those same regions. Our results show that the best-supported, explanatory models of cetacean diversity included SST, while the addition of satellitederived measures of productivity did not improve predictive capacity. Marine mammal richness globally peaks around $40^{\circ} \mathrm{N}$ and $\mathrm{S}$, and may result more directly from optimal SST at these latitudes rather than high oceanic productivity.
\end{abstract}

KEY WORDS: Biodiversity · Productivity · Sea surface temperature $\cdot$ Cetacean

Resale or republication not permitted without written consent of the publisher

\section{INTRODUCTION}

Which factors control the diversity of marine species over large scales? This question has become a major research focus in marine ecology, in part motivated by efforts to safeguard species against further diversity loss. Recently, Schipper et al. (2008) presented a novel pattern of marine mammal diversity based on expert opinions, which featured strong latitudinal peaks in

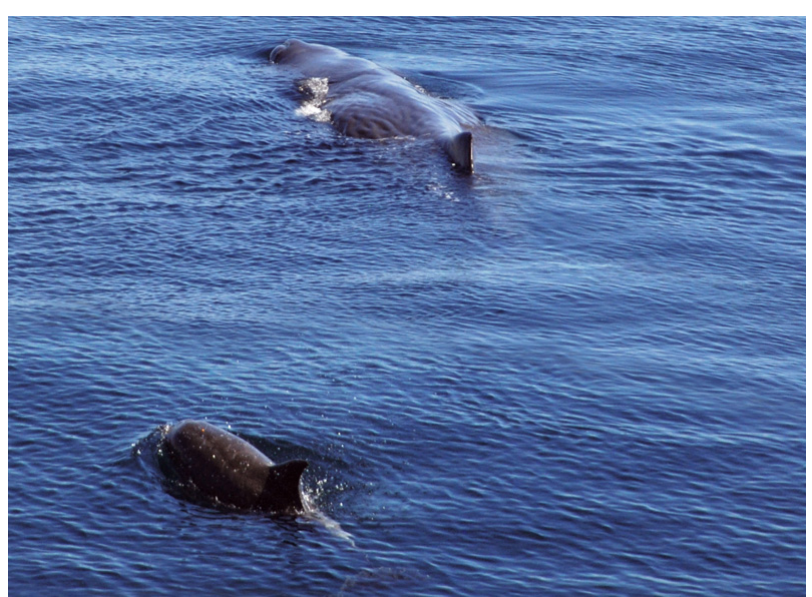

Sperm whale Physeter macrocephalus and bottlenose dolphin Tursiops truncatus in the Sea of Cortez, Mexico; regional diversity of whales and dolphins is more strongly correlated with temperature than with primary productivity.

Photo: Catalina Gomez

species richness around $40^{\circ} \mathrm{N}$ and $\mathrm{S}$. The authors suggested that such hotspots of marine mammal richness are associated with peaks of primary productivity at those latitudes (Field et al. 1998). This hypothesis contrasts with other global assessments of marine diversity, which empirically revealed sea surface temperature (SST) as a major driving variable for foraminiferan zooplankton (Rutherford et al. 1999), tuna and billfish (Worm et al. 2005) and deep-water cetacean richness (Whitehead et al. 2008). Productivity measures, however, were not directly tested in those previous analyses.

Here we try to distinguish empirically between these 2 hypotheses. We asked whether productivity, SST, or a combination of these factors may explain patterns of cetacean richness in the open ocean. Due to the high mobility of most cetaceans, we used real-time empiri- 
cal field data, rather than time-averaged assessments, in order to shed light on this question. Hence, we used a large sightings data set of deep-water cetaceans (non-coastal whales and dolphins), in combination with in situ measurements of SST and 3 different measures of satellite-derived primary productivity made at the same time and place. We tested the hypotheses that temperature, productivity, or both correlate with spatial patterns of genus richness in deep-water cetaceans at a scale of tens to hundreds of kilometers. This scale was chosen because it correlates with the scale of dayto-day movement in most cetaceans (Whitehead 2003, his Table 3.5).

\section{METHODS}

We compiled incidental records of 2352 sightings of groups of cetaceans during field studies directed at 2 species of deep-water whales, sperm whales Physeter macrocephalus and northern bottlenose whales Hyperoodon ampullatus. The sightings were made between 1998 and 2007 in the northwest Atlantic and eastern Pacific Oceans from auxiliary sailing vessels. These records are a subset of the sighting database first presented by Whitehead et al. (2008), matched to satellitederived productivity measurements made by the Seaviewing Wide Field-of-view Sensor (SeaWiFS) satellite, which have been available since 1998. We concatenated sightings of the same species made within $1 \mathrm{~h}$, and omitted all sightings of $P$. macrocephalus and $H$. ampullatus (the target species of the research at sea), sightings without identification to genus and those in waters $<200 \mathrm{~m}$ depth.

We divided the sightings record into blocks of $b$ sightings such that among the sightings in each block there were differences of no more than $30 \mathrm{~d}, 1000 \mathrm{~km}$ or $4^{\circ} \mathrm{C}$ SST. Sightings were sequentially omitted from the analysis until a block of $b$ consecutive sightings was found satisfying these conditions. We carried out all the analyses with $b=5$. In a previous analysis (Whitehead et al. 2008) we varied $b$, but found this made no substantive difference to the results.

We obtained productivity estimates $\left(\mathrm{mg} \mathrm{C} \mathrm{m} \mathrm{m}^{-2} \mathrm{~d}^{-1}\right)$ from the Ocean Productivity Site (www.science. oregonstate.edu/ocean.productivity/index.php), which provides estimates of net primary productivity (hereby referred to as productivity) generated from SeaWiFS satellite data by the following models: the standard vertically generalized production model (VGPM; Behrenfeld \& Falkowski 1997), the Eppley vertically generalized production model (Eppley-VGPM), which uses Eppley's (1972) exponential function for the temperature-dependence of photosynthetic efficiencies, and the carbon-based production model (CbPM;
Behrenfeld et al. 2005). These and other models of ocean productivity were compared and evaluated by Carr et al. (2006). Data were available by month and $10^{\circ}$ latitude by $10^{\circ}$ longitude rectangle. The year, month, latitude and longitude (from GPS) of each cetacean sighting were used to match a productivity value for each of the 3 measures.

Our measure of biodiversity, genus richness $(y)$, was the number of different cetacean genera in each block of sightings and could range from 1 to $b(=5)$. We fitted general linear models, inverse polynomials (Nelder 1966), and generalized linear models (with binomial error) to the values of $y$. For the general linear models, we assumed that $y$ was normally distributed about a function of SST (as recorded in situ at 06:00 h on the day of sighting), depth (from www.gfdl.noaa.gov/ products/vis/data/datasets/etopo2_topography.html, logged), absolute latitude (from GPS-determined positions), satellite-measured productivity (as described above), as well as polynomial functions and combinations of these factors (Table 1). SST, depth, latitude and productivity for each block were the means of the values for each sighting within the block. We also used models including the categorical variables ocean (Atlantic or Pacific) and area (study areas within oceans), but as these variables had little utility in predicting diversity in either our previous analysis (Whitehead et al. 2008) or this analysis, we do not present these results. The models included either SST or productivity as well as the 4 combinations of linear and quadratic models of SST and productivity (Table 1). Minimal Akaike's information criterion (AIC) indicated the preferred model, while support for other models was suggested by $\triangle \mathrm{AIC}$, the difference between the AIC of a model and that of the preferred model (Burnham \& Anderson 2002).

\section{RESULTS}

The 3 measures of productivity at the locations of cetacean sightings were well correlated: VGPM vs. Eppley-VGPM, r = 0.945; VGPM vs. CbPM, r = 0.795; Eppley-VGPM vs. CbPM, $r=0.757(\mathrm{n}=2352)$. There was no strong linear correlation between SST and productivity (VGPM vs. SST, r = 0.150; Eppley-VGPM vs. $\mathrm{SST}, \mathrm{r}=0.277$; CbPM vs. SST, $\mathrm{r}=-0.107 ; \mathrm{n}=2352$ ). Although there was much scatter, the VGPM productivity measure unimodally peaked at ca. $17^{\circ} \mathrm{C}$ (Fig. 1) and declined at higher temperatures. The other 2 productivity measures showed weaker relationships with SST.

The revised data sets including a measure of productivity contained 173 blocks of 5 sightings (using VGPM and Eppley-VGPM productivities), or 175 blocks 
Table 1. Fits of general linear models to genus richness data of deep-water cetaceans, indicated using the change in Akaike's information criterion $(\triangle \mathrm{AIC})(0$ : model with most support, in bold $_{i}<2$ : some support ${ }_{i}>2$ : no support). Predictors are sea surface temperature (SST), depth, absolute latitude (lat) and primary productivity (prod) using 3 measures: standard vertically generalized production model (VGPM); Eppley-VGPM; and carbon-based production model $(\mathrm{CbPM}) ; \mathrm{a}, \mathrm{b}$, and $\mathrm{c}$ are fitted parameters of the inverse polynomial models

\begin{tabular}{|c|c|c|c|}
\hline Model & VGPM & Eppley-VGPM & $\mathrm{CbPM}$ \\
\hline null & 33.60 & 33.60 & 33.62 \\
\hline SST & 1.97 & 1.97 & 2.89 \\
\hline $\mathbf{S S T}_{,} \mathbf{S S T}^{2}$ & 0.00 & 0.00 & 0.00 \\
\hline $\mathrm{SST}_{,} \mathrm{SST}^{2}{ }_{,} \mathrm{SST}^{3}$ & 1.97 & 1.97 & 1.98 \\
\hline lat & 27.56 & 27.56 & 27.43 \\
\hline lat,lat ${ }^{2}$ & 6.45 & 6.45 & 7.55 \\
\hline lat,lat ${ }^{2}$, lat $^{3}$ & 5.59 & 5.59 & 5.66 \\
\hline $\mathrm{SST} \mathrm{SST}^{2}$, lat & 1.49 & 1.49 & 1.50 \\
\hline $\mathrm{SST}_{\text {,SST}}{ }^{2}$ lat, lat ${ }^{2}$ & 0.91 & 0.91 & 1.06 \\
\hline $\mathrm{SST}_{,} \mathrm{SST}^{2}, \mathrm{lat} \mathrm{lat}^{2}, \mathrm{lat}^{3}$ & 2.71 & 2.71 & 2.81 \\
\hline Depth & 30.23 & 30.23 & 30.28 \\
\hline $\mathrm{SST} \mathrm{SST}^{2}$, depth & 1.56 & 1.56 & 1.56 \\
\hline 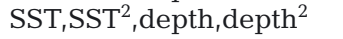 & 3.55 & 3.55 & 3.55 \\
\hline prod & 34.84 & 35.05 & 34.58 \\
\hline prod,prod ${ }^{2}$ & 35.25 & 36.79 & 36.25 \\
\hline $\operatorname{prod} \operatorname{prod}^{2}, \operatorname{prod}^{3}$ & 34.32 & 33.04 & 35.02 \\
\hline prod,prod $^{2}$, lat & 27.39 & 30.26 & 29.15 \\
\hline prod,prod $^{2}$, lat,lat $^{2}$ & 6.75 & 8.79 & 9.61 \\
\hline prod, $\operatorname{prod}^{2}$, lat, lat ${ }^{2}$, lat $^{3}$ & 7.62 & 8.47 & 8.06 \\
\hline prod,prod $^{2}$, depth & 30.23 & 33.97 & 33.54 \\
\hline prod,prod $^{2}$, depth,depth ${ }^{2}$ & 31.95 & 35.27 & 34.65 \\
\hline SST,prod & 3.92 & 3.01 & 4.89 \\
\hline $\mathrm{SST}, \mathrm{SST}^{2}$, prod & 1.37 & 0.63 & 1.48 \\
\hline SST,prod,prod ${ }^{2}$ & 3.86 & 5.00 & 5.86 \\
\hline $\mathrm{SST}_{,} \mathrm{SST}^{2}$, prod, prod $^{2}$ & 3.09 & 2.60 & 3.31 \\
\hline $\mathrm{SST} /(\mathrm{a}+\mathrm{b} \cdot \mathrm{SST})$ & 0.65 & 0.65 & 0.86 \\
\hline $\mathrm{SST} /\left(\mathrm{a}+\mathrm{b} \cdot \mathrm{SST}+\mathrm{c} \cdot \mathrm{SST}^{2}\right)$ & 1.55 & 1.55 & 1.52 \\
\hline $\operatorname{prod} /(\mathrm{a}+\mathrm{b} \cdot \mathrm{prod})$ & 37.60 & 37.60 & 37.35 \\
\hline $\operatorname{prod} /\left(\mathrm{a}+\mathrm{b} \cdot \operatorname{prod}+\mathrm{c} \cdot \operatorname{prod}^{2}\right)$ & 138.92 & 32.13 & 108.28 \\
\hline
\end{tabular}

(CbPM productivity), as compared to 356 blocks for the full data set (as used by Whitehead et al. 2008). The difference is due to the lack of SeaWiFS-derived productivity measures before 1998, as well as to cells with missing productivity data. The used blocks contained a mean of 2.7 different genera. Median spans of sightings within blocks were $0.4^{\circ} \mathrm{C} \mathrm{SST},<1 \mathrm{~d}$, and $25 \mathrm{~km}$.

In general, diversity increased slightly with productivity, no matter which measure was used (Fig. 2). In particular, there seemed to be an increase in diversity at the highest productivities (Fig. 2). With CbPM productivity, a steady, slow increase in diversity with productivity was apparent, but with the 2 VGPM measures, cetacean diversity seemed only to increase at very high productivities (1000 to $1500 \mathrm{mg} \mathrm{C} \mathrm{m}^{-2} \mathrm{~d}^{-1}$ ). These trends could arise because productivity drives diversity, or because both are related to some other factor, such as SST. Our models tried to distinguish such causes.

When we analyzed cetacean richness in relation to temperature, productivity, and their combined effects, we found that results were very similar, irrespective of the error structure used. Thus, only the results from the general linear model (with normal error) are presented in Table 1. Results were similar for all 3 measures of productivity. Models without SST had essentially no support $(\triangle \mathrm{AIC}>5)$ whether they included measures of productivity or not (Table 1). Models including both productivity and SST had considerably less support than the same models without productivity (Table 1). As with the full data set (Whitehead et al. 2008), the quadratic SST model with diversity peaking at about $21^{\circ} \mathrm{C}$ was best supported.

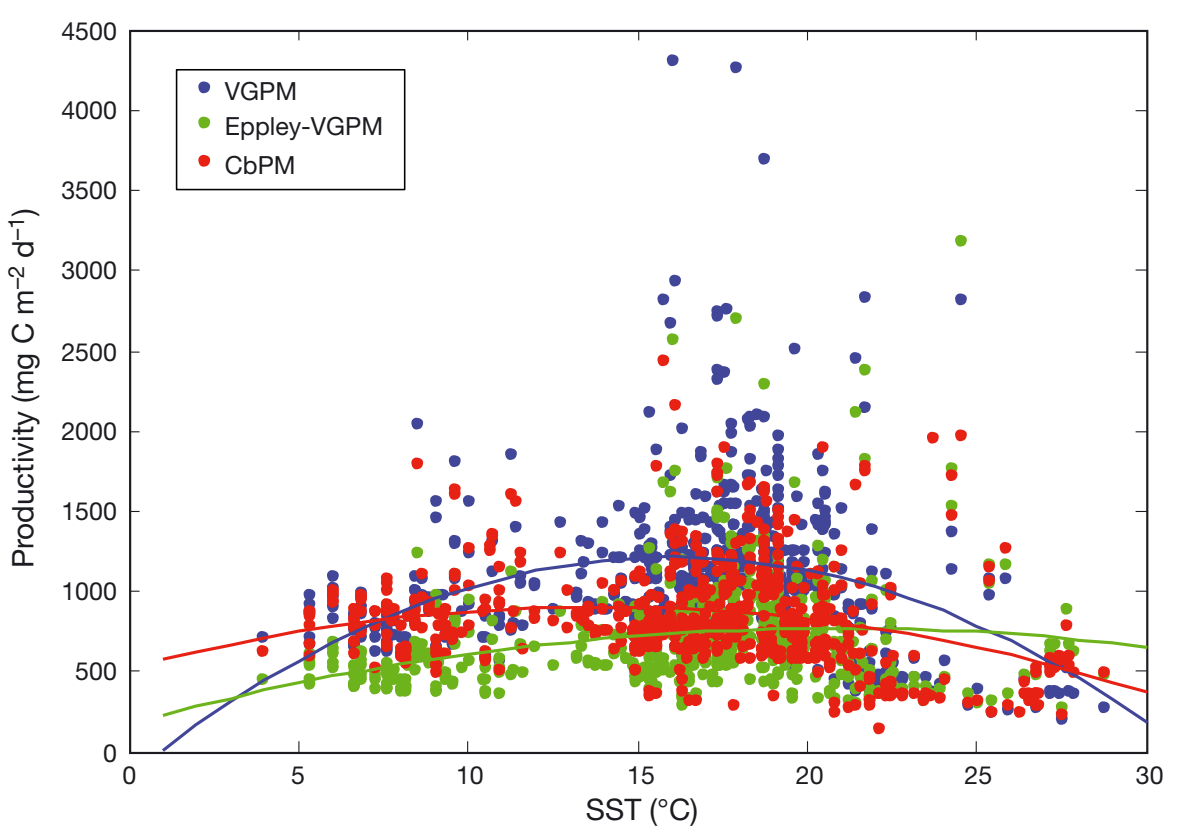

Fig. 1. Deep-water cetacean sightings in relation to productivity and sea surface temperature (SST). Each point is a unique cetacean sighting. Colors identify different estimates of primary productivity: standard vertically generalized production model (VGPM); EppleyVGPM; and carbon-based production model (CbPM). Lines indicate fitted quadratic polynomials 

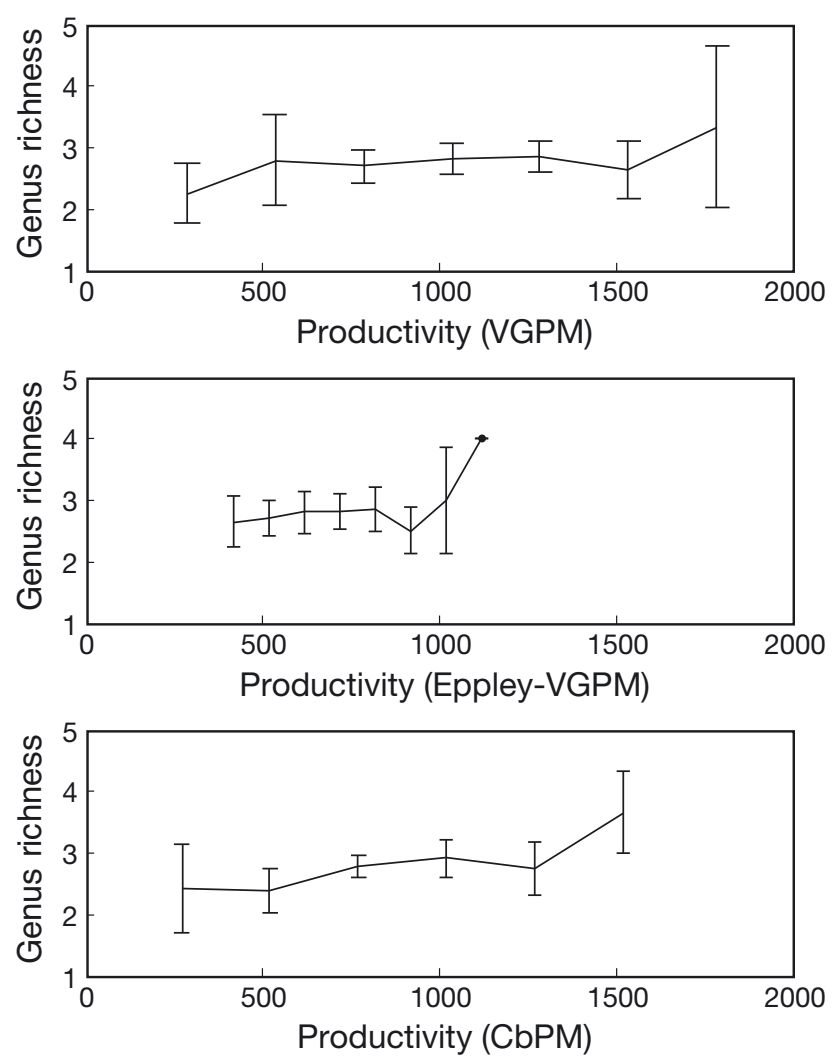

Fig. 2. Mean $( \pm \mathrm{SE})$ genus richness of deep-water cetaceans with 3 measures of productivity: standard vertically generalized production model (VGPM); Eppley-VGPM; and carbonbased production model (CbPM). Data are in $\mathrm{mg} \mathrm{C} \mathrm{m}^{-2} \mathrm{~d}^{-1}$

\section{DISCUSSION}

Our analysis represents the first direct test of the hypothesis that primary productivity may drive patterns of marine species richness. It revealed that none of the 3 measures of productivity predicts deep-water cetacean biodiversity particularly well at the scale at which these animals operate (10s to $100 \mathrm{~s}$ of $\mathrm{km}$ ). Useful explanatory models needed to include SST, and once this was accounted for, the addition of satellitederived measures of productivity made no significant contribution. Thus, we suspect that observed peaks in marine mammal species richness at around $40^{\circ} \mathrm{N}$ and $\mathrm{S}$ (Schipper et al. 2008) result more directly from optimal SSTs for marine mammal biodiversity at these latitudes (Whitehead et al. 2008) rather than from belts of high oceanic productivity. This hypothesis is further supported by analyses performed to explain patterns of zooplankton (Rutherford et al. 1999) and fish diversity (Worm et al. 2005). These studies used chlorophyll a concentration as a predictor, which tends to correlate well with primary productivity in pelagic ecosystems (Behrenfeld \& Falkowski 1997). Both analyses found that SST correlated best with patterns of species richness, whereas chlorophyll a was not a good predictor.

Why does deep-water cetacean diversity correlate so particularly with SST? From an ecological perspective, diversity is a function of niche overlap. The niche of a particular cetacean species is multidimensional, yet we hypothesize that water depth and SST are particularly prominent in distinguishing habitats of different species. Each of these factors directly relates to species physiology and anatomy through adaptations for diving, energetics and thermal regulation (e.g. Noren 2004, Koopman 2007). Here we largely removed water depth as a factor by limiting our study to deep waters. Within deep-water species, different taxa have distinctive thermal ranges, typically spanning about $10^{\circ} \mathrm{C}$ (Whitehead et al. 2008). With niche widths of about $10^{\circ} \mathrm{C}$ distributed overlapping across a global SST range of about $30^{\circ} \mathrm{C}$, diversity will naturally peak near the centre of this range. In addition, this physiologically based relationship between cetacean diversity and SST may be reinforced by similarly structured diversity patterns in prey species, including zooplankton (Rutherford et al. 1999, Beaugrand et al. 2002) and fish (Worm et al. 2005, Boyce et al. 2008, Hiddink \& ter Hofstede 2008).

Our results contrast with experimental microcosm studies suggesting that diversity responds strongly to changes in productivity, often in a unimodal (humpshaped) fashion (Kassen et al. 2000). Observational studies at larger scales, however, have often failed to resolve consistent patterns, particularly for animals (Mittelbach et al. 2001). We note that most studies were performed on land (e.g. Mittelbach et al. 2001), and some discrepancies may be explained by differences in scale (Chase \& Leibold 2002). Primary productivity clearly affects marine animal abundance (Ware \& Thomson 2005), but seems not to determine diversity to the same degree, especially once abundance is controlled as a confounding factor by rarefaction, as in the present study.

Our use of in situ measurements of both diversity and explanatory variables contrasts with assessments of diversity derived from geographical ranges of taxa derived from expert opinions and overlayed on timeaveraged explanatory variables (e.g. Schipper et al. 2008). Such analyses may reflect the diversity of potentially occurring organisms, which is likely to be quite different from realized patterns at any point in time, which are influenced by large-scale movements of cetaceans as well as temporal variability in oceanographic conditions.

The robustness of our findings largely depends on the reliability of satellite-derived productivity measures reflecting real productivity patterns at the spatial (10s to $100 \mathrm{~s}$ of $\mathrm{km}$ ) and temporal (days to weeks) scales 
considered. Further studies will be needed to disentangle the relationships between SST, productivity and diversity in other regions and for other taxa. If these results hold true more generally, this would suggest that global increases in SST, as observed and predicted by the Intergovernmental Panel on Climate Change and others, will rearrange the global diversity patterns for marine mammals, as well as other pelagic taxa (reviewed by Worm \& Lotze 2009). Changes in productivity, for example through increased nitrogen deposition (Duce et al. 2008), would be relatively less likely to have an impact on diversity.

Acknowledgements. Thanks to D. Boyce and R. O'Malley for assistance in accessing ocean productivity measures, as well as to C. Muir, B. Würsig and 2 anonymous reviewers for critically reading the manuscript. The authors gratefully acknowledge support from the National Science and Engineering Research Council of Canada and the Census of Marine Life (FMAP Program) as funded by the Sloan Foundation.

\section{LITERATURE CITED}

Beaugrand G, Reid PC, Ibañez F, Lindley JA, Edwards M (2002) Reorganization of North Atlantic marine copepod diversity and climate. Science 296:1692-1694

Behrenfeld MJ, Falkowski PG (1997) Photosynthetic rates derived from satellite-based chlorophyll concentration. Limnol Oceanogr 42:1-20

Behrenfeld MJ, Boss E, Siegel DA, Shea DM (2005) Carbonbased ocean productivity and phytoplankton physiology from space. Global Biogeochem Cycles 19:1-14

Boyce DG, Tittensor DP, Worm B (2008) Effects of temperature on global patterns of tuna and billfish richness. Mar Ecol Prog Ser 355:267-276

Burnham KP, Anderson DR (2002) Model selection and multimodel inference: a practical information-theoretic approach. Springer-Verlag, New York, NY

Carr M, Friedrichs MAM, Schmeltz M, Noguchi Aita M and others (2006) A comparison of global estimates of marine primary production from ocean color. Deep-Sea Res Part II 53:741-770

Chase JM, Leibold MA (2002) Spatial scale dictates the productivity-biodiversity relationship. Nature 416:427-430

Editorial responsibility: Michael Castellini,

Fairbanks, Alaska, USA
Duce RA, LaRoche J, Altieri K, Arrigo KR and others (2008) Impacts of atmospheric anthropogenic nitrogen on the open ocean. Science 320:893-897

Eppley RW (1972) Temperature and phytoplankton growth in the sea. Fish Bull 70:1063-1085

Field CB, Behrenfeld MJ, Randerson JT, Falkowski P (1998) Primary production of the biosphere: integrating terrestrial and oceanic components. Science 281:237-240

> Hiddink JG, ter Hofstede R (2008) Climate induced increases in species richness of marine fishes. Global Change Biol 14:453-460

Kassen R, Buckling A, Bell G, Rainey PB (2000) Diversity peaks at intermediate productivity in laboratory microcosms. Nature 406:508-512

Koopman H (2007) Phylogenetic, ecological, and ontogenetic factors influencing the biochemical structure of the blubber of odontocetes. Mar Biol 151:277-291

Mittelbach GG, Steiner CF, Scheiner CF, Gross KL and others (2001) What is the observed relationship between species richness and productivity? Ecology 82:2381-2396

- Nelder JA (1966) Inverse polynomials, a useful group of multi-factor response functions. Biometrics 22:128-141

> Noren S (2004) Buffering capacity of the locomotor muscle in cetaceans: correlates with postpartum development, dive duration, and swim performance. Mar Mamm Sci 20: $808-822$

> Rutherford S, D'Hondt S, Prell W (1999) Environmental controls on the geographic distribution of zooplankton diversity. Nature 400:749-753

Schipper J, Chanson JS, Chiozza F, Cox NA and others (2008) The status of the world's land and marine mammals: diversity, threat, and knowledge. Science 322:225-230

- Ware DM, Thomson RE (2005) Bottom-up ecosystem trophic dynamics determine fish production in the Northeast Pacific. Science 308:1280-1284

Whitehead H (2003) Sperm whales: social evolution in the ocean. Chicago University Press, Chicago, IL

> Whitehead H, McGill B, Worm B (2008) Diversity of deepwater cetaceans in relation to temperature: implications for ocean warming. Ecol Lett 11:1198-1207

Worm B, Lotze HK (2009) Changes in marine biodiversity as an indicator of climate change. In: Letcher T (ed) Climate change: observed impacts on Planet Earth. Elsevier, Amsterdam, p 263-279

> Worm B, Sandow M, Oschlies A, Lotze HK, Myers RA (2005) Global patterns of predator diversity in the open oceans. Science 309:1365-1369

Submitted: December 8, 2009; Accepted: April 14, 2010

Proofs received from author(s): May 23, 2010 